\title{
Heavy Vehicle Propulsion Materials Program
}

Sidney Diamond

U.S. Department of Energy

D. Ray Johnson

Oak Ridge National Laboratory 
SAE routinely stocks printed papers for a period of three years following date of publication. Direct your orders to SAE Customer Sales and Satisfaction Department.

Quantity reprint rates can be obtained from the Customer Sales and Satisfaction Department.

To request permission to reprint a technical paper or permission to use copyrighted SAE publications in other works, contact the SAE Publications Group.

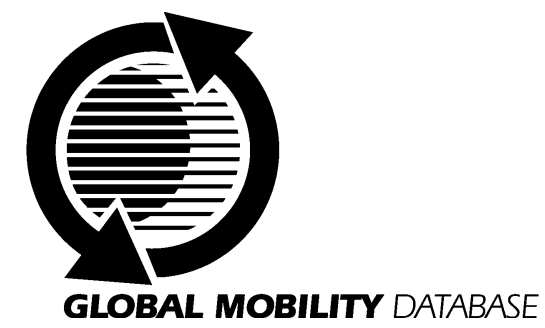

AII SAE papers, standards, and selected books are abstracted and indexed in the Global Mobility Database

\section{ISSN 0148-7191}

Positions and opinions advanced in this paper are those of the author(s) and not necessarily those of SAE. The author is solely responsible for the content of the paper. A process is available by which discussions will be printed with the paper if it is published in SAE Transactions. For permission to publish this paper in full or in part, contact the SAE Publications Group.

Persons wishing to submit papers to be considered for presentation or publication through SAE should send the manuscript or a 300 word abstract of a proposed manuscript to: Secretary, Engineering Meetings Board, SAE.

\section{Printed in USA}




\title{
Heavy Vehicle Propulsion Materials Program
}

\author{
Sidney Diamond \\ U.S. Department of Energy \\ D. Ray Johnson \\ Oak Ridge National Laboratory
}

\begin{abstract}
The objective of the Heavy Vehicle Propulsion Materials Program is to develop the enabling materials technology for the clean, high-efficiency diesel truck engines of the future. The development of cleaner, higher-efficiency diesel engines imposes greater mechanical, thermal, and tribological demands on materials of construction. Often the enabling technology for a new engine component is the material from which the part can be made. The Heavy Vehicle Propulsion Materials Program is a partnership between the Department of Energy (DOE), and the diesel engine companies in the United States, materials suppliers, national laboratories, and universities. A comprehensive research and development program has been developed to meet the enabling materials requirements for the diesel engines of the future. Advanced materials, including high-temperature metal alloys, intermetallics, cermets, ceramics, amorphous materials, metal- and ceramic-matrix composites, and coatings, are investigated for critical engine applications.
\end{abstract}

\section{INTRODUCTION}

The Office of Heavy Vehicle Technologies (OHVT) envisions the development of a fuel-flexible, energy-efficient, near-zero-emissions, heavy-duty U.S. diesel engine technology devolving into all truck classes. Development of innovative diesel engine technology is a real and viable strategy for reducing energy requirements for both commercial transport services and the rapidly growing multipurpose vehicle market (pickups, vans, and sport utility vehicles). ${ }^{1}$

The primary goals of the OHVT are as follows:

1. Develop by 2002 the diesel engine enabling technologies to support large-scale industry dieselization of light trucks, achieving a 35\% fuel efficiency improvement over equivalent gasoline-fueled trucks.

2. Develop by 2004 the enabling technology for a class 7-8 truck with a fuel efficiency of $10 \mathrm{mpg}$ (at $65 \mathrm{mph}$ ) which will meet prevailing emission standards, using either diesel or a liquid alternative fuel.
3. Develop by 2004 diesel engines with fuel flexibility and a thermal efficiency of $50 \%$ with liquid alternative fuels, and a thermal efficiency of $50 \%$ with dedicated gaseous fuel.

An assessment of technical barriers to the goals of OHVT identified a number of materials issues. ${ }^{2}$ Higher efficiency engines will require higher peak and brake mean effective pressures, higher stresses on components and higher temperatures resulting in increased thermal fatigue, and requirements for greater precision and lighter weight. Requirements include materials for advanced combustion chamber components, cylinder heads and engine blocks; low-inertia materials for turbochargers; materials for improved insulation of the exhaust system; improved coatings and other thermal barriers; materials for advanced fuel systems to improve combustion and reduce emissions; materials for advanced piston/ring/cylinder components to reduce friction; and lowdensity materials to increase the engine power-specific weight to a level competitive with SI engines.

Emission control will require improved catalysts, better particulate traps, alternate aftertreatment technologies, better lubricant control, and improved fuel injection systems. Materials requirements include more durable catalyst materials, supports, and wash coats; durable materials for effective, regenerable particulate traps; improved materials for lubricant control to reduce particulate emissions; and high-strength, non-scuffing, wearresistant materials for high-pressure fuel injection systems to reduce particulate emissions.

Fuel-flexible engines require materials that are chemically compatible with alternate fuels, and that are durable in the presence of low-lubricity alternate fuels. Materials requirements include stable, corrosion-resistant materials for glow plugs; and durable, wear- and corrosion-resistant intake valves, valve seats, and valve guides to increase the durability of natural gas engines.

The OHVT Advanced Heavy Vehicle Technologies R\&D program has the following two-pronged approach:

1. A partnership with the domestic transportation industry, energy supply industry, other federal agencies, 
and research and development organizations; to develop and to promote the acceptance of high-efficiency engine technologies and alternative fuel utilization technologies for trucks.

2. Continuing development of key enabling technologies, such as materials, to ensure market success.

\section{HEAVY VEHICLE PROPULSION MATERIALS ORGANIZATION}

The Heavy Vehicle Propulsion Materials Program is organized as a government - industry - university partnership to develop enabling materials technology. The DOE Office of Heavy Vehicle Technologies, assisted by the DOE Oak Ridge Operations Field Office, leads the program. The technical management is delegated to the Oak Ridge National Laboratory. The research and development is carried out by the domestic heavy duty diesel engine manufacturers and their materials and component suppliers, the national laboratories, and universities.

The candidate materials developed in the program are chosen to overcome critical engine technology barriers, i.e., by technology pull from the diesel engine industry in response to the goals of the OHVT. Candidate materials include the following:

- high-temperature alloys,

- intermetallic alloys,

- ceramic-metal composites (cermets),

- structural ceramics,

- bulk amorphous alloys,

- ceramic and metal-matrix composites, and

- thermal barrier and wear coatings.

The Heavy Vehicle Propulsion Materials Program is presently organized around key engine technologies:

FUEL SYSTEMS - A project is ongoing with participation by engine companies, national laboratories, and universities. These efforts are directed toward development of advanced fuel systems to reduce emissions and improve efficiency. Engine companies continue to develop highpressure fuel systems that require improved, highstrength, scuff-resistant materials for fuel injector plungers and more durable alloys for fuel injector tips. Highstrength ceramics and new cermet (ceramic-metal composites) materials are being developed and characterized. High-speed fuel injector systems based on "smart materials" are being developed that will allow greater control of fuel injection, resulting in reduced emissions and higher engine efficiency. Piezo and magnetostrictive materials are being developed for use in this new class of injectors. Novel machining and manufacturing technologies are being investigated for producing fuel system components with higher precision and at acceptable cost.
EXHAUST AFTERTREATMENT - The reduction of NOx and particulate emissions is critically important to OHVT's program, and is highly materials dependent. New programs have begun to develop advanced catalyst systems for NOx reduction and particulate filter technology to remove particulates from the exhaust stream. These efforts include studies of the degradation mechanisms that lead to premature failure of the catalysts; contribution to the development of improved catalysts; and development of materials, fabrication technology, and testing of particulate filters.

VALVE TRAIN - Materials are an enabling technology for durable valve-train components in advanced engines including valves, valve guides, valve seats, cam followers, and rocker arms. A new program is in place to develop lightweight valve train materials for use in all classes of heavy-duty diesel engines. Efforts include materials development, testing and life prediction, and manufacturing technology such as joining, machining, and inspection.

STRUCTURAL AND INSULATING MATERIALS - The design of advanced, low-emission, high-efficiency engines results in increased mechanical and thermal stresses on structural components in the engine block and cylinder head. The anticipated use of exhaust-gas recirculation (EGR) to lower emissions will result in corrosion and erosion of components as well. Programs are in place to develop advanced materials and manufacturing methods for these components. High-strength engine block and cylinder head designs and materials are being developed. Insulated structural hot-section components are being developed for use in very-high-efficiency engines. Materials technology, including improved materials, nondestructive and destructive testing and characterization, and manufacturing technology, is being developed.

STANDARDS - The commercialization of new materials technologies is dependent on having standard testing methods which are accepted by the industry. OHVT has ongoing projects which facilitate the voluntary standards activities by the American Society for Testing and Materials (ASTM) and international standards activities by the International Standards Organization (ISO). In addition, OHVT participates in an international program under the International Energy Agency (IEA) to facilitate standards development. Many U.S. industrial laboratories, national laboratories, and universities are involved.

\section{FUTURE WORK}

The ongoing effort to determine the critical R\&D needs of the U.S. heavy vehicle industry will continue. A workshop is planned for the fall of 1999, which will lead to a revised multiyear program plan. Many of the new activities 
described above will be continued into fiscal year 2001 and beyond. Current plans for new R\&D activities include the following:

- improved technology for drilling very small holes in fuel injector tips,

- new concepts for precision machining of components,

- new cermet and metal-matrix composites,

- fatigue-resistant, high-temperature alloys for exhaust manifolds and turbochargers,

- new methods of joining dissimilar materials, such as a valve head to valve shaft and turbo rotor to shaft, and

- new catalyst and particulate filter materials and designs.

\section{CONCLUSIONS}

Advanced materials offer the opportunity to improve the emissions; noise, vibration, and harshness (NVH); and performance of diesel engines. The design of advanced components for low-emission, high-efficiency diesel engines may push the performance envelope for materials of construction past the point of reliable operation. Higher mechanical and tribological stresses and higher temperatures of advanced designs limit the engine designer. However, advanced materials allow the design of components that may operate reliably at higher stresses and temperatures, thus enabling more efficient engine designs. Materials R\&D encompasses not only the development and application of new materials, but also the critical work on characterization, from microstructure through physical and mechanical properties.

The Office of Heavy Vehicle Technologies has ambitious goals for the development of clean, high-efficiency trucks. An assessment of technical barriers to the attainment of OHVT's goals identified a number of requirements for improved materials, materials characterization and testing data and methodology, and manufacturing technology. The Heavy Vehicle Propulsion Materials Program was initiated as a government-industry-university partnership to develop enabling materials technology for heavy vehicle engines. The candidate materials to be investigated in the program are chosen by technology pull from the diesel engine manufacturers and their component suppliers. A comprehensive program is ongoing, including projects in

- materials for fuel systems,

- materials for exhaust aftertreatment,

- materials for valve-train components,

- structural and insulating materials, and

- materials standards.

Tentative technical plans have been developed through 2001 and beyond. A technology assessment and program planning activity is continuing, and is expected to lead to a published multiyear program plan in the first quarter of the year 2000.

\section{ACKNOWLEDGMENTS}

Research sponsored by the U.S. Department of Energy, Assistant Secretary for Energy Efficiency and Renewable Energy, Office of Transportation Technologies, as part of the Heavy Vehicle Propulsion Materials Program, under contract DE-AC05-96OR22464 with Lockheed Martin Energy Research Corporation.

\section{REFERENCES}

1. Multiyear Program Plan for 1998-2002, DOE/ORO2071, U.S. DOE, Office of Heavy Vehicle Technologies (OHVT), Office of Transportation Technologies, August 1998.

2. OHVT Technology Roadmap, DOE/OSTI-11690, U.S. DOE, Office of Transportation Technologies, Office of Transportation Technologies, October 1997.

\section{CONTACT}

Sidney Diamond can be reached at the Department of Energy, Office of Transportation Technologies, Forrestal Building, EE-33, 1000 Independence Avenue, S.W., Washington, DC 20585. His e-mail address is sid.diamond@hq.doe.gov. 